\title{
Room-temperature electrophosphorescence from an all-organic material
}

\author{
Pavel Anzenbacher, Jr., ${ }^{\star}$ César Pérez-Bolívar, Shin-ya Takizawa, Valentina Brega \\ Department of Chemistry and Center for Photochemical Sciences, Bowling Green State \\ University, Bowling Green (OH) 43403, USA \\ E-mail: pavel@bgsu.edu
}

\begin{abstract}
Materials displaying both fluorescence and phosphorescence emission in solutions and solid state at room temperature are described. The present materials comprise diphenylphosphino and bromosubstituents that cause intersystem crossing and corresponding triplet emission without the presence of heavy metals. Electroluminescence with a significant contribution of phosphorescence was observed in the experimental $(\mathrm{Ph})$ OLEDs.
\end{abstract}

Keywords: Electrophosphorescence; Triplet; Synthesis; Spectroscopy

\section{Introduction}

The phosphorescence in organic materials originates in forbidden transitions.[1] In OLEDs, due to the spin statistics of electron-hole recombination, the electrical excitation generates three triplets for every singlet exciton.[2] Thus, this feature makes the triplet-based electro-luminescence properties an area of high interest.[3] In organic materials, triplet radiative decay rates are low, and therefore the triplet decay is often difficult to observe, particularly at room temperature where nonradiative decay often predominates.[4]

However, by employing molecules with high phosphorescence quantum yields, the quantum efficiency of OLEDs may be significantly improved.[5] Such phosphorescent molecules often include heavy-metal atoms that improve the harvesting of singlets and their intersystem crossing (ISC) to triplet states, a process which further increases the observable electrophosphorescence.[6] On the other hand, the phosphorescence quantum yield of organic materials is usually very low due to negligible heavy-atom effect and a corresponding lack of ISC.[7] Nevertheless, phosphorescence at room temperature (RTP) has been reported for various polycyclic aromatic hydrocarbons in fluid solutions in the presence of a high concentration of heavy atoms such as thallium,[8],[9] or in cases where the nonradiative triplet deactivation is prevented by the formation of inclusion complexes with cyclodextrins[10] or incorporation of the luminophore into a crystal lattice.[11] Thus, RTP has been used to identify organic compounds.[12] However, the determination of traces of hydrocarbon compounds requires that these molecules are adsorbed onto a solid substrate or included in rigid matrixes.[13],[14],[15]

In solid state devices, Baldo et al. reported phosphorescence sensitization improving the emission efficiency of small-molecule-based OLEDs.[16] Similarly, triplet excitons were observed to transfer energy from the phosphorescent complex bis[2-(4,6-difluorophenyl)pyridinato- $\left.C^{2}, N\right]$ (picolinato)iridium(III) (FIrpic) to 4,4'-N,N'-dicarbazole-biphenyl (CBP) with a lower triplet energy which then resulted in CBP tripletsensitization.[17] Goushi et al. reported the phosphorescence enhancement of 4,4'-bis[N-(1-naphthyl)- $N$ phenylamino]biphenyl (a-NPD) using fac-tris(2-phenylpyridine) iridium(III), a donor with higher triplet energy than that of $\alpha$-NPD.[18] The phosphorescence of 4,4'-N,N'-dicarbazole-biphenyl (CBP), 4,4'-bis[N-(p-tolyl)-N-phenyl-amino]biphenyl (TPD), 1,1-bis[(di-4-tolylamino)phenyl]cyclo-hexane (TAPC) and tris(8-hydroxyquinoline) aluminum (III) $\left(\mathrm{Alq}_{3}\right)$ have also been sensitized by phosphorescent donor molecules.[18],[19] However, the phosphorescence emission observed for these films was obtained at very low temperatures, in most cases at $8 \mathrm{~K}$. In the present study, however, we show the phosphorescence and electrophosphorescence originating from all-organic materials at room temperature.

\section{Experimental}




\subsection{General Procedures}

${ }^{1} \mathrm{H}$ NMR and ${ }^{13} \mathrm{C}$ NMR spectra were recorded using a Bruker $300 \mathrm{MHz}$ spectrometer. ${ }^{31} \mathrm{P}$ NMR spectra were recorded using a Varian $400 \mathrm{MHz}$. MALDI MS spectra were recorded using a MALDI-TOF Bruker Omiflex using 2',5'-Dihydroxyacetophenone matrix.

Cyclic voltammetry measurements were carried out using a three-electrode cell (Pt working electrode) with $\mathrm{Pt}$ wire as an auxiliary electrode. Millimolar DCM solutions containing $0.1 \mathrm{M}$ tetrabutylammonium perchlorate were used. All potentials were referenced against the $\mathrm{Ag} / \mathrm{AgNO}$ reference electrode and each measurement was calibrated using a ferrocene/ferrocenium $\left(\mathrm{Fc} / \mathrm{Fc}^{+}\right)$redox system. Under these conditions the ferrocene/ferrocenium couple potential was determined to be $+0.240 \mathrm{~V}$ vs $\mathrm{Ag} / \mathrm{AgNO}_{3}$.

The UV-vis spectra were recorded using an HP diode array spectrophotometer. The absorbance of the measured solutions was between 0.1 and 0.3 . Emission spectra were recorded using an Edinburgh Analytical Instruments (FL/FS 900) spectrofluorimeter. The fluorescence quantum yields of the luminophores were measured as a function of the excitation wavelength using Tryptophan in water at $\mathrm{pH} 7$ as a standard $(\Phi=0.20)$ by the method described by Crosby.[20]

The devices were fabricated using indium tin oxide (ITO) coated glass slides (sheet resistance 20 $\Omega$ /square) according to our published procedure.[21] The ITO substrates were cleaned using surfactant, water, 2-propanol, and acetone, then dried and exposed to ozone plasma. A $25 \mathrm{~nm}$ film of PEDOT:PSS was spin-coated from a $1.25 \%$ aqueous dispersion of Clevios® $P$ and dried at $145^{\circ} \mathrm{C}$ for 10 minutes. The OLED layers were deposited by resistive evaporation at a rate of 1 $\AA / s$. The thicknesses of the individual layers are described below. The electroluminescent $(E L)$ characteristics were measured using a Keithley 2400 source-meter and a Hamamatsu Photonic multi-channel analyzer C10027 (PMA-12) and an integrating sphere. All measurements were carried out under nitrogen at room temperature.

\subsection{Synthesis and characterization}

Synthesis of 2-bromo-7-diphenylphosphine-9,9'-bis(2-ethylhexyl)fluorene. (1) A solution of 2,7-dibromo-9,9'-bis(2-ethylhexyl)fluorene $(5.0 \mathrm{~g}, 9.1 \mathrm{mmol})$ in THF (160 ml) was cooled down to $70^{\circ} \mathrm{C}$ in an acetone-dry ice bath. $n$-buthyllithium $(3.7 \mathrm{ml}, 9.25 \mathrm{mmol})$ was added to the solution, and the resulting solution was stirred at $-70^{\circ} \mathrm{C}$ for 1 hour. After that, the temperature was allowed to increase slowly to room temperature. The solution was stirred at room temperature for 3 hours before cooling down to $-70^{\circ} \mathrm{C}$ again. After 20 minutes chlorodiphenylphosphine $(3.6 \mathrm{ml}, 20.0$ $\mathrm{mmol}$ ) was added. The resulting mixture was stirred overnight allowing the temperature to increase slowly to room temperature. The reaction mixture was poured into methanol. The mixture was filtered through a filter paper, and the filtrate was transferred to a round bottom flask. After solvent evaporation, the resulting oil was digested in hexanes, and the solvent was evaporated. The resulting oil was digested in a mixture of dichloromethane and methanol. The solvents were evaporated and a clear oil was obtained. The oil was purified by column chromatography using a mixture of hexane and dichloromethane as eluent (9:1). Yield (4.15 g, $70 \%) .{ }^{1} \mathrm{H}$ NMR $\left(\mathrm{CDCl}_{3}\right), \delta(\mathrm{ppm}): 0.42$ (td, $\left.5 \mathrm{H}, J=2.07,7.15 \mathrm{~Hz}\right) ; 0.50$ (td, $3 \mathrm{H}, J=1.69,7.15 \mathrm{~Hz}$ ); $0.71(\mathrm{~m}, 15 \mathrm{H}) ; 0.877(\mathrm{~m}, 9 \mathrm{H}) ; 1.83(\mathrm{~m}, 2 \mathrm{H}) ; 7.33(\mathrm{~m}, 11 \mathrm{H}) ; 7.22(\mathrm{dd}, 1 \mathrm{H}, J=3.57,8.10 \mathrm{~Hz}) ; 7.43$ (dd, $1 \mathrm{H}, J=7.72,1.69 \mathrm{~Hz}) ; 7.47(\mathrm{t}, 1 \mathrm{H}, J=1.88 \mathrm{~Hz}) ; 7.53(\mathrm{~d}, 1 \mathrm{H}, J=8.10 \mathrm{~Hz}) ; 7.63(\mathrm{~d}, 1 \mathrm{H}, J=7.72$ $\mathrm{Hz}) .{ }^{13} \mathrm{C}$ APT NMR $\left(\mathrm{CDCl}_{3}\right), \delta(\mathrm{ppm}): 10.00 \mathrm{CH}_{3}, 10.42 \mathrm{CH}_{3}, 13.99 \mathrm{CH}_{3}, 14.02 \mathrm{CH}_{3}, 22.68 \mathrm{CH}_{2}$, 22.75 $\mathrm{CH}_{2}$, 26.59 $\mathrm{CH}_{2}, 27.17 \mathrm{CH}_{2}, 27.97 \mathrm{CH}_{2}, 28.32 \mathrm{CH}_{2}, 33.50 \mathrm{CH}_{2}, 33.85 \mathrm{CH}_{2}, 34.59 \mathrm{CH}, 34.66$ $\mathrm{CH}, 44.27 \mathrm{CH}_{2}, 44.51 \mathrm{CH}_{2}, 55.18 \mathrm{C}, 119.63 \mathrm{CH}, 120.89 \mathrm{C}, 121.02 \mathrm{CH}, 121.14 \mathrm{CH}, 126.57 \mathrm{C}$, $127.35 \mathrm{CH}, 127.45 \mathrm{CH}, 128.37 \mathrm{CH}, 128.47 \mathrm{CH}, 128.64 \mathrm{CH}, 129.91,130.07,132.25 \mathrm{C}, 133.51 \mathrm{C}$ $(\mathrm{d}, J=2.19 \mathrm{~Hz}), 133.77 \mathrm{C}(\mathrm{d}, J=2.19 \mathrm{~Hz}), 135.19 \mathrm{C}, 137.34 \mathrm{C}, 139.68 \mathrm{C} .{ }^{13} \mathrm{C}$ DEPT135 NMR $\left(\mathrm{CDCl}_{3}\right), \delta$ (ppm): $10.06 \mathrm{CH}_{3}, 10.53 \mathrm{CH}_{3}, 14.11 \mathrm{CH}_{3}, 18.53 \mathrm{CH}_{2}, 22.83 \mathrm{CH}_{2}, 26.67 \mathrm{CH}_{2}, 27.25$ $\mathrm{CH}_{2}, 28.03 \mathrm{CH}_{2}, 28.39 \mathrm{CH}_{2}, 33.58 \mathrm{CH}_{2}, 33.92 \mathrm{CH}_{2}, 34.66 \mathrm{CH}, 44.32 \mathrm{CH}_{2}, 44.57 \mathrm{CH}_{2}, 58.57 \mathrm{C}$, $119.62 \mathrm{CH}, 121.03 \mathrm{CH}, 121.54 \mathrm{CH}, 127.32 \mathrm{CH}, 128.39 \mathrm{CH}, 128.47 \mathrm{CH}, 128.65 \mathrm{CH}, 129.91 \mathrm{CH}$, $133.51 \mathrm{C}(\mathrm{d}, J=1.64 \mathrm{~Hz}), 133.75 \mathrm{C}(\mathrm{d}, J=1.64 \mathrm{~Hz}) .{ }^{31} \mathrm{P}$ NMR $\left(\mathrm{CDCl}_{3}\right), \delta(\mathrm{ppm}):-2.88$. MALDITOF Calculated $\mathrm{C}_{41} \mathrm{H}_{50} \mathrm{P}_{1} \mathrm{Br}_{1}$ : 653.23. MALDI-TOF Experimental: 654.27.

Synthesis of 2-bromo-7-diphenylphosphineoxide-9,9'-bis(2-ethylhexyl)fluorene. (2) A solution of 2-bromo-7-diphenylphosphine-9,9'-bis(2-ethylhexyl)fluorene $(3 \mathrm{~g}, 4.6 \mathrm{mmol}$ ) in $30 \mathrm{ml}$ of dichloromethane was prepared and stirred. After 15 minutes, $0.5 \mathrm{ml}$ of hydrogen peroxide were 
added dropwise to the solution. The resulting solution was stirred at room temperature overnight, and the reaction mixture was poured into distilled water. The mixture was extracted 3 times with $30 \mathrm{ml}$ of dichloromethane. The organic layers were combined and dried over anhydrous sodium sulfate, and the solvent was evaporated under reduced pressure. The resulting oil was dried under vacuum for 12 hours. Yield $(2.76 \mathrm{~g}, 90 \%)$. ${ }^{1} \mathrm{H}$ NMR $\left(\mathrm{CDCl}_{3}\right), \delta(\mathrm{ppm}): 0.38(\mathrm{td}, 4 \mathrm{H}, J=3.01$, $7.15 \mathrm{~Hz}$ ); $0.51(\mathrm{dd}, 2 \mathrm{H}, J=2.26,7.72 \mathrm{~Hz}) ; 0.54(\mathrm{dt}, 2 \mathrm{H}, J=2.07,6.9 \mathrm{~Hz}), 0.71(\mathrm{~m}, 16 \mathrm{H}) ; 0.83(\mathrm{~m}$, $9 \mathrm{H}) ; 1.88(\mathrm{~m}, 2 \mathrm{H}) ; 7.46(\mathrm{~m}, 6 \mathrm{H}) ; 7.52(\mathrm{~m}, 3 \mathrm{H}) ; 7.59(\mathrm{~d}, 1 \mathrm{H}, J=8.1 \mathrm{~Hz}) ; 7.66(\mathrm{~m}, 5 \mathrm{H}) ; 7.75(\mathrm{~m}, 1 \mathrm{H})$. ${ }^{13} \mathrm{C}$ NMR $\left(\mathrm{CDCl}_{3}\right), \delta(\mathrm{ppm}): 9.98,10.41,14.02,22.70,26.52,27.10,27.22,28.07,28.37,33.53$, $33.99,34.68,44.27,44.55,55.50,119.68,121.04,121.74,121.95,127.41,127.56,127.66$, $128.38,128.51,130.08,130.24,131.87,132.06,132.15,139.09 .{ }^{31} \mathrm{P} \mathrm{NMR}\left(\mathrm{CDCl}_{3}\right), \delta(\mathrm{ppm})$ : 30.27. MALDI-TOF Calculated $\mathrm{C}_{41} \mathrm{H}_{50} \mathrm{O}_{1} \mathrm{P}_{1} \mathrm{Br}_{1}$ : 669.43. MALDI-TOF Experimental: 669.43 .

\section{Results and discussion}

\subsection{Synthesis}

The synthesis of 1 and 2 (Fig. 1) was performed following the outline in Scheme 1.

Thus, the starting material, 2,7-dibromo-9,9-bis-2-ethylhexyl-fluorene (DBEHF), was treated with 1 equiv. of $n$-butyllithium followed by the addition of chlorodiphenylphosphine according to the modified procedure previously used to synthesize bis-phosphinated compounds such as compound 3.[22] The 2-bromo-7-diphenyl-phosphine-9,9'-bis(2-ethylhexyl)fluorene 1 product was then treated with hydrogen peroxide to obtain the corresponding phosphine-oxide material 2. Compound $\mathbf{3}$ was synthesized using a similar procedure.
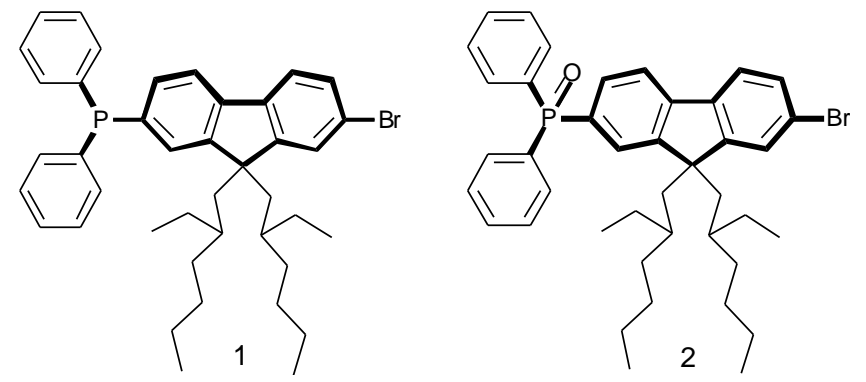

Fig. 1. Structure of compounds 1 and 2.

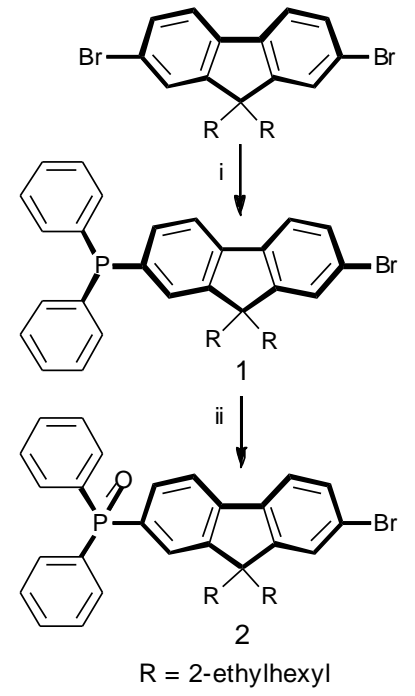

Scheme 1. Synthetic scheme for compounds 1 and 2. i) $n$-BuLi. THF, $-70^{\circ} \mathrm{C}$ to $25^{\circ} \mathrm{C}$; $0{ }^{\circ} \mathrm{C}$, chlorodiphenylphosphine $0^{\circ} \mathrm{C}$ to $25^{\circ} \mathrm{C}, 70 \%$; ii) $\mathrm{H}_{2} \mathrm{O}_{2}$, DCM, reflux, $90 \%$. 


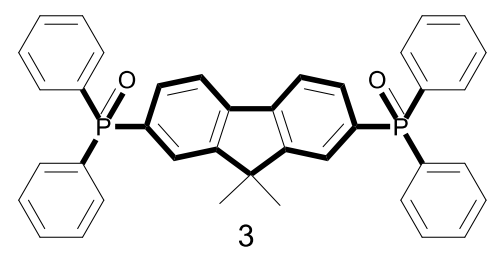

Fig. 2. Compound used for comparison.

\subsection{HOMO-LUMO and electronic structure}

The values of HOMO and LUMO (Table 1) for compounds 1 and 2 were determined from electrochemistry and compared to the previously published data for compound 3.[23]

The obtained experimental values showed that the phosphine group in $\mathbf{1}$ induced a stronger stabilizing effect while reducing the HOMO energy in respect to 2,7-dibromo-bis(2-ethylhexyl)fluorene (DBEHF) and in a lesser extent also phosphine oxide compound 2. In general, the LUMO levels proved to be more dependent on the substituent. Relatively speaking, the $\mathrm{P}=\mathrm{O}$ affected the LUMO for $0.2 \mathrm{eV}$ more than the phosphine group in 1. This is in agreement with the observed results for compound $\mathbf{3}$, in which two phosphine oxide groups lowered the LUMO to a value of $-2.4 \mathrm{eV}$ (ca $0.3 \mathrm{eV}$ lower than the LUMO of 2). It was also observed that the LUMO levels for $\mathbf{1}$ and $\mathbf{2}$ were similar to the previously published compound $\mathbf{3}$. These LUMO levels can be aligned effectively to the LUMO of commonly used electron transporting materials, hole-blocking materials and the cathode work functions and are likely to be suitable for use in OLEDs.

Table 1. HOMO and LUMO measured from cyclic voltammetry and estimated from gas phase for compounds 1 and 2.

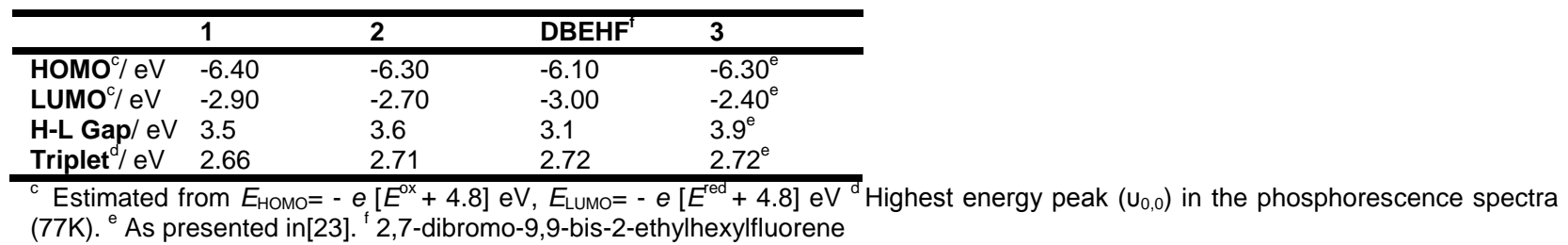

\subsection{Photophysical Properties}

When the solutions of compounds $\mathbf{1}$ and 2 in dichloromethane (DCM) were excited at their respective absorption maxima (270 $\mathrm{nm}$ and $280 \mathrm{~nm}$, respectively) (Figure 3) two simultaneous emissions were observed: the first localized at 344 and the second at $509 \mathrm{~nm}$ for 1 and 339 and $516 \mathrm{~nm}$ for 2 (Figure 4). The lifetime of the emissions in the UV range of the spectrum were in the order of nanoseconds (Table 2) suggesting that these emission bands (344 nm in 1, and 339 in 2) correspond to fluorescence. 


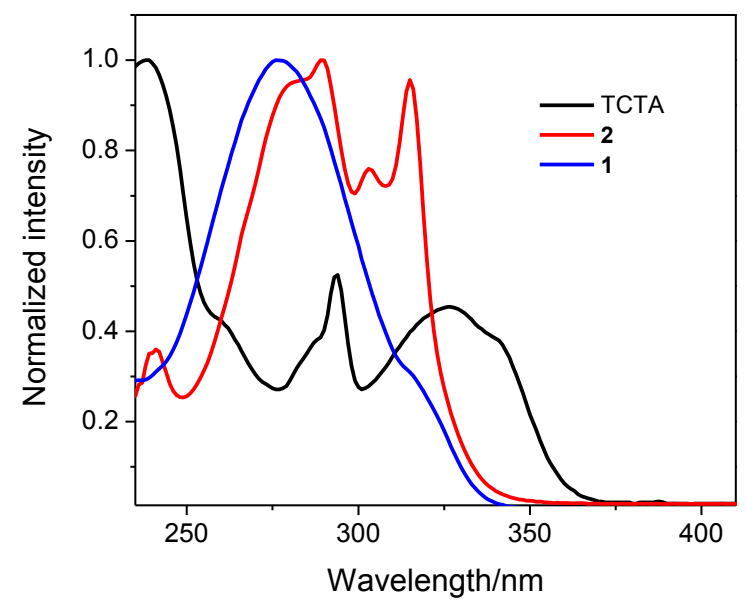

Fig. 3. Absorption spectra of $\mathbf{1}$ and $\mathbf{2}$ in dichloromethane solutions including absorption spectrum of TCTA.

To investigate the long-lived emission observed at $450-600 \mathrm{~nm}$, the emission scans were acquired using a micro second flash lamp with delayed detection $0.5 \mu \mathrm{s}$. Here, the solutions of 1 and 2 showed long-lived (a microsecond time range) emission even in the cases where no argon was used to purge the samples. Thus, the long-lived emission was assigned to phosphorescence. The relative intensity ratio of fluorescence and phosphorescence $\left(I_{\mathrm{Fl}} / \mathrm{I}_{\mathrm{Ph}}\right)$ was 4.62 for compound 1 and 14.8 for compound 2, respectively. These values clearly show that the phosphorescence intensity for compound $\mathbf{1}$ was remarkably higher than that of compound $\mathbf{2}$ (Figure 4).

Table 2. Photophysical properties in DCM solutions.

\begin{tabular}{llllllll}
\hline Compound & $\begin{array}{l}\lambda_{\mathrm{FL}} \\
/ \mathrm{nm}\end{array}$ & $\begin{array}{l}\mathrm{T}_{\mathrm{FL}} \\
\mathrm{ns}\end{array}$ & $\boldsymbol{\theta}_{\mathrm{FL}}$ & $\begin{array}{l}\mathbf{R T} \\
\boldsymbol{\lambda}_{\mathrm{PH}} \\
/ \mathrm{nm}\end{array}$ & $\begin{array}{l}\mathbf{T}_{\mathrm{PH}} \\
/ \mu \mathrm{S}\end{array}$ & $\begin{array}{l}\mathbf{7 7 K} \\
\boldsymbol{\lambda}_{\mathrm{PH}} \\
/ \mathrm{nm}\end{array}$ & $\begin{array}{l}\mathbf{T}_{\mathrm{PH}} \\
/ \mathrm{ms}\end{array}$ \\
\hline $\mathbf{1}$ & 344 & 1.69 & 0.18 & 509 & 53.12 & 457 & 19.95 \\
$\mathbf{2}$ & 339 & 1.13 & 0.34 & 516 & 75.49 & 455 & 26.70 \\
\hline
\end{tabular}

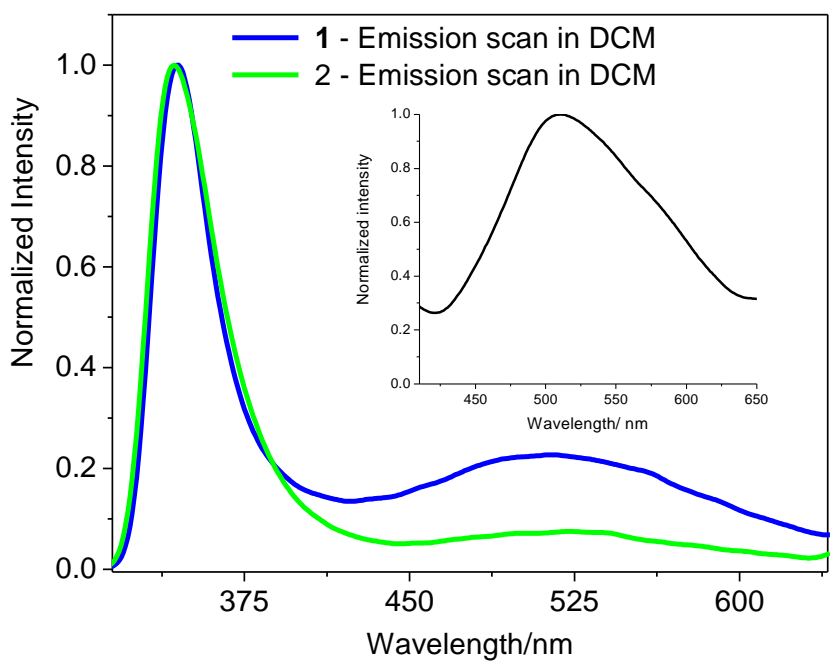

Fig. 4. Emission scan of $\mathbf{1}$ and 2 in DCM solutions acquired at room temperature. Excitation wavelength set at 270 $\mathrm{nm}$ for $\mathbf{1}$, and $280 \mathrm{~nm}$ for $\mathbf{2}$. Inset: phosphorescence at room temperature for $\mathbf{1}$ acquired with delayed detection (0.5 $\mu \mathrm{s})$. 
To understand these features, DFT (B3LYP/6-31G* level) calculations of HOMO and LUMO distributions were performed.

As shown in Figure 5, left panel, for compound 1, the HOMO distribution is spread over the whole molecule to include the non-oxidized phosphine moiety, fluorene and bromine moieties. These two elements (phosphorus and the bromine) can induce a high magnitude of spin-orbit coupling resulting in a more effective intersystem crossing. A similar situation is also observed in the corresponding LUMO distribution (Figure 5, right). In contradistinction, in the oxidized phosphine of 2 (Figure 6) the frontier orbitals do not include the electronic communication with the diphenylphosphine oxide moiety, and the HOMO and LUMO densities are centered on the fluorene with some of the density on the bromine atom. The fact that in compound 2 the phosphorus atom does not participate in the HOMO/LUMO explains the lower phosphorescence intensity of compound 2.
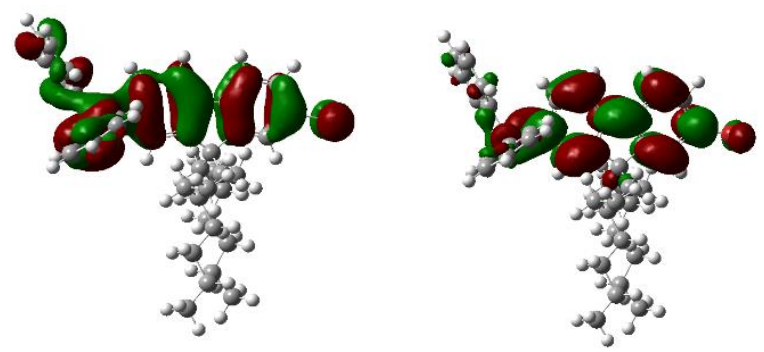

Fig. 5. HOMO (left) and LUMO (right) distribution for 2-bromo-7-diphenylphosphine-9,9-bis(2-ethylhexyl)fluorene (1).
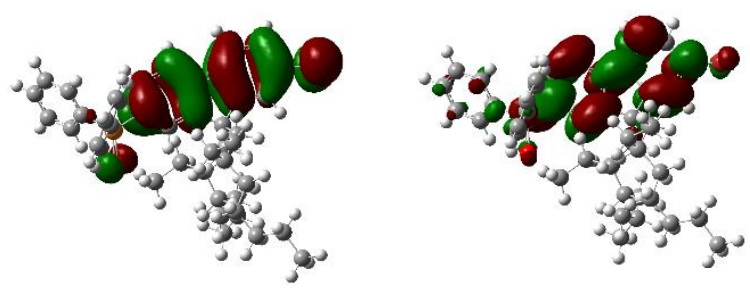

Fig. 6. HOMO (left) and LUMO (right) distribution for 2-bromo-7-diphenylphosphineoxide-9,9-bis(2ethylhexyl)fluorene (2).

For comparison, we also recorded the emission spectra of 2,7-dibromo-9,9-bis(2ethylhexyl)fluorene (DBEHF). At room temperature, the DCM solution of DBEHF displayed a weak fluorescence peak at $333 \mathrm{~nm}$. Even when the solution was purged with argon and the delayed detection was used it was not possible to observe any long-lived emission. However, at $77 \mathrm{~K}$ the phosphorescence with well-structured features was observed for all three compounds, $\mathbf{1}$, 2 and DBEHF (Figure 7). The phosphorescence spectra recorded at 77K from all three compounds, 1, 2 and DBEHF showed interesting similarity regardless the substitution suggesting that the fluorene is the main feature controlling the photophysical properties.

The data in Table 3 and Figure 8 describe the room temperature emission properties recorded using thin-films prepared using compounds $\mathbf{1}$ and $\mathbf{2}$. 


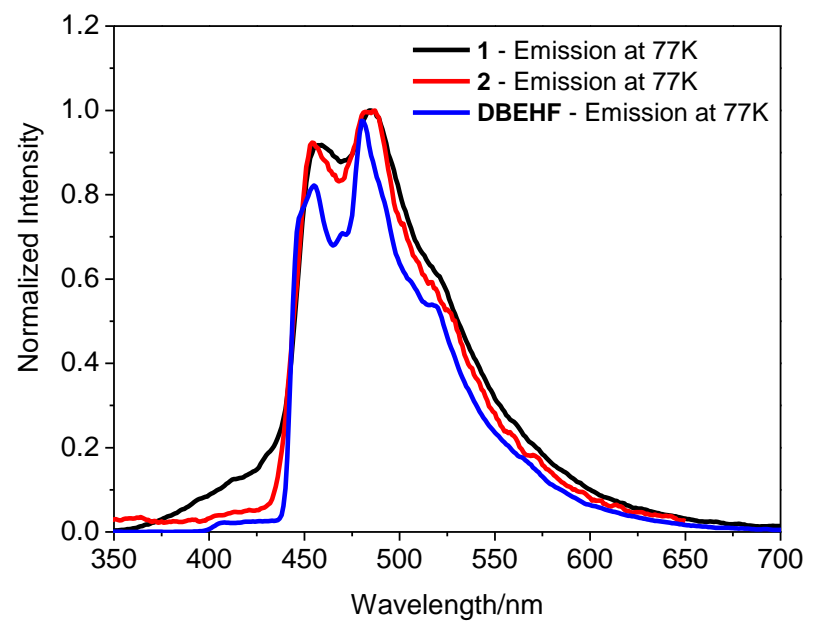

Fig. 7. Phosphorescent emission of 1, 2 and DBEHF acquired at 77K using delayed detection after excitation.

Table 3. Solid state photophysical properties for compounds $\mathbf{1}$ and $\mathbf{2}$ recorded at room temperature.

\begin{tabular}{llll}
\hline Thin Film & $\boldsymbol{\lambda}_{\mathrm{FL}} / \mathbf{n m}$ & $\boldsymbol{\Lambda}_{\mathrm{PH}} / \mathbf{n m}$ & $\mathbf{T}_{\mathrm{PH}} / \mathbf{m s}$ \\
\hline 1 neat film & 366 & 524 & 2539,644 \\
2 neat film & 365 & 513 & - \\
1- PMMA suspension & 343 & 455,487 & 304,1742 \\
2 - PMMA suspension & 343 & 464,480 & 344,1781 \\
\hline
\end{tabular}

The spectra for compound 1 recorded in the neat film (Figure 8) resembled the emission spectrum recorded in the DCM solution, but did not show strong the maximum at $510 \mathrm{~nm}$ previously attributed to the phosphorescence (Figure 4). This is assumed to be due to the efficient oxygen diffusion into the thin film of 1 . However, the phosphorescence at $510 \mathrm{~nm}$ is clearly observable with delayed detection. When the spectra of $\mathbf{1}$ were recorded in the polymethylmethacrylate (PMMA) suspension, both the fluorescence and phosphorescence part of the spectrum were found to be red-shifted compared to the spectra of the neat films. The phosphorescence part of the spectrum was clearly observable (using delayed detection) including vibronic progressions.

Similarly to $\mathbf{1}$, compound $\mathbf{2}$ showed a broad spectra that can be deconvoluted into fluorescence and phosphorescence, which is particularly clear in the spectra recorded with delayed detection (Figure 9). The fluorescence peak for a film of a neat compound 2 (black trace) displayed a red shift with respect to the solution spectra. A similar red shift was recorded for the two RTP phosphorescence spectra recorded in PMMA (blue trace) and in neat thin film (red trace). This has been observed in phosphine oxides, which can form extended structures through strong $\mathrm{P}-\mathrm{O}$ and $\mathrm{H}-\mathrm{C}$ interactions.[24] Burrows et al.[22] observed a similar phenomenon and attributed these shifts to aggregation rather than the formation of excimers, as no change was observed in either the UV-visible absorption or the excitation scan for corresponding emissions. 


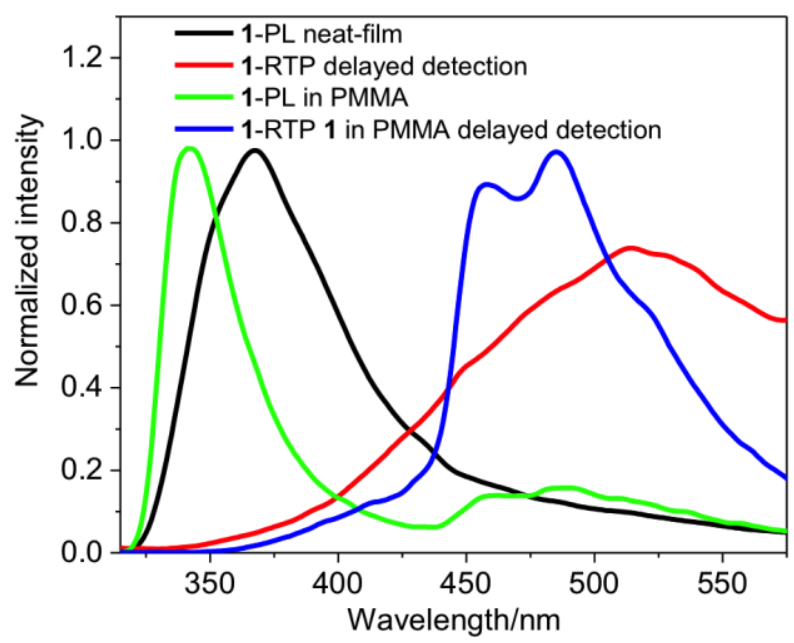

Fig. 8. Emission of neat thin-film and PMMA suspension of 1. Phosphorescence at room temperature acquired with delayed detection.

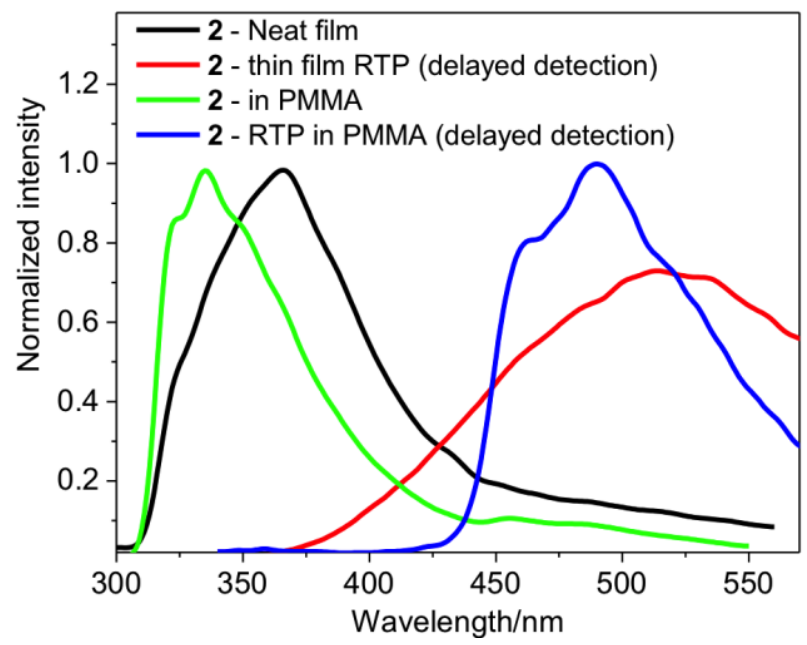

Fig. 9. Emission of neat thin-film and PMMA suspension of 2. Phosphorescence at room temperature acquired with delayed detection.

\subsection{Electroluminescence of compound 1}

The preliminary electroluminescence studies were performed with compound $\mathbf{1}$ as it showed stronger room-temperature phosphorescence contribution compared to 2. Thus, we prepared electrophosphorescent light-emitting devices (PhOLEDs) using spincoating method. The devices comprised a poly(ethylene-dioxythiophene):Polystyrene sulfonate (PEDOT: PSS) $(40 \mathrm{~nm})$ layer, followed by the spin-coating of $\mathbf{1}$ and hole transport layer of 4,4',4"-Tri(carbazol-9$\mathrm{yl}$ )triphenylamine (TCTA) blend from a solution of $10 \mathrm{mg} / \mathrm{mL}$ of concentration $(45 \mathrm{~nm})$. Then, an electron transport layer of 1,3,5-Tri(1-phenyl-1 H-benzo[d]imidazol-2-yl)phenyl (TPBI) $(30 \mathrm{~nm})$ was deposited using resistive evaporation. The devices were finalized by the deposition of cathode of a thin layer of cesium fluoride $(1 \mathrm{~nm})$ and aluminum $(100 \mathrm{~nm})$. The mixture of hole-transporting material and emissive material is described by the mass ratio $(\mathrm{m} / \mathrm{m})$. The LUMO energy level of 1 $(-2.90 \mathrm{eV})$ lies on a closer level to the LUMO energy of TPBI $(-2.7 \mathrm{eV})$ compared to LUMO of TCTA (-2.4), and it is expected that the electrons will be confined and trapped by 1.

The device configurations for $\mathbf{A} 1$ and $\mathbf{B} 1$ were as follows:

A1: PEDOT:PSS/ TCTA-1 (1:1)/TPBI /Cathode

B1: PEDOT:PSS/ TCTA-1 (1:9) /TPBI /Cathode 
In essence, both devices A1 and B1 gave similar electroluminescence spectra. The difference was the marginal performance of the device B1 (cf. max. luminance of $570 \mathrm{Cd} / \mathrm{m}^{2}$ for $\mathbf{A} 1$ and max. luminance of $76 \mathrm{Cd} / \mathrm{m}^{2}$ for B1, Table 4). This is attributed to a low charge mobility in $\mathbf{1}$ in the heavily doped emissive layer of B1 consisting of $90 \%$ of 1 . The observed electroluminescence $(E L)$ of the OLEDs was centered on 510-520 nm. No UV-emission was observed in the EL spectrum. Devices A1 and B1 showed rather wide emission instead of a well-defined emission peak. This broadening of the peaks could be a consequence of strong intermolecular interactions that involve the phosphine moiety. The EL for compound 1 resembles the phosphorescence emission observed in the neat thin-film of compound 1 (Figure 10). Figure 10 shows the electroluminescence of the device $\mathbf{A} 1$ and thin-film phosphorescence of 1 (time-gated spectrum). This observation is especially important considering not only that the emission resembles the long-lived triplet state emission from thin-films, but also does not show any fluorescence. Previously, Burrows et al.[22] observed a weak emission between 400 and $520 \mathrm{~nm}$ for a single layer device of 2,7-bis(diphenylphosphine oxide)-9,9-dimethylfluorene, compound 3 above. This emission between 400 and $520 \mathrm{~nm}$ was attributed to either aggregates or electrophosphorescence. Based on our observations of the phosphorescence in the films of 1 and 2, we can attribute this behavior to electrophosphorescence. Importantly, according to their observations[25] the excimer emission is not responsible for the tail in the EL spectrum. Last but not least, we did not observe any contribution from TCTA and TPBI in the EL spectrum for the devices A1 and B1.

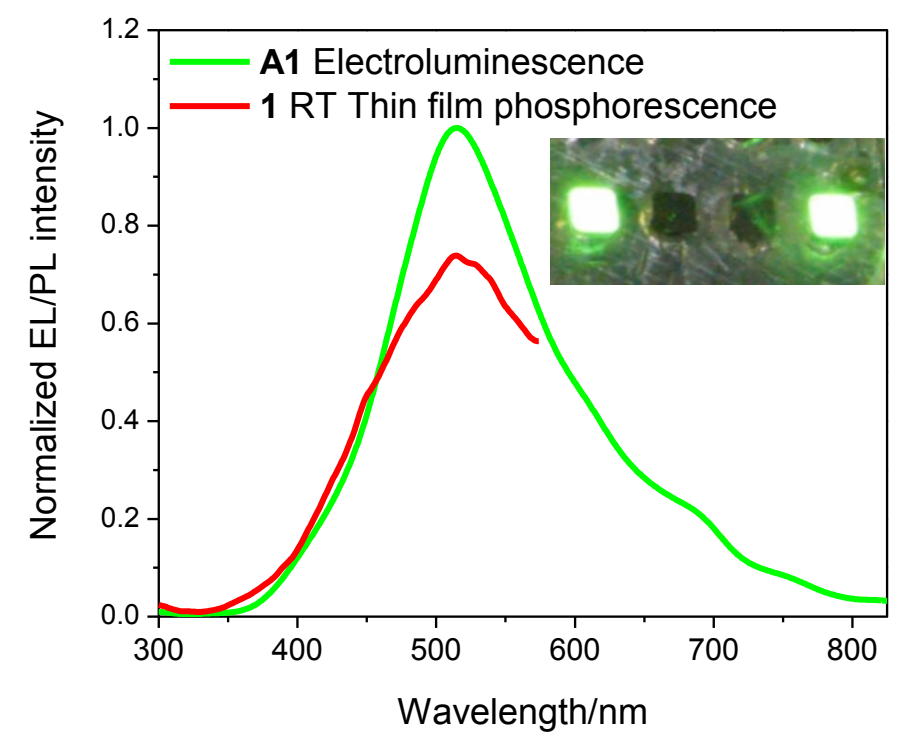

Fig. 10. Electroluminescence spectra for device A1. Inset: A digital photograph of working pixel shows green electroluminescence corresponding attributed to electrophosphorescence.

Table 4. Electroluminescence (EL) characterization of devices.

\begin{tabular}{llllll}
\hline $\begin{array}{l}\text { Device } \\
\text { Structure }\end{array}$ & $\begin{array}{l}\text { EL max } \\
/ \mathbf{n m}\end{array}$ & $\begin{array}{l}\text { Max. } \\
\text { Luminance } \\
/ \mathbf{C d} / \mathbf{m}^{2}\end{array}$ & $\begin{array}{l}\text { Turn-on } \\
\text { Voltage } \\
/ \mathbf{V}\end{array}$ & $\begin{array}{l}\text { Max. } \\
\text { EQE }\end{array}$ & $\begin{array}{l}\mathbf{C d} / \mathbf{m}^{2} \\
\text { @ Max. } \\
\text { EQE }\end{array}$ \\
\hline A1 & 510 & 574 & 10.5 & 0.25 & 60 \\
B1 & 507 & 76.5 & 13.8 & 0.15 & 58 \\
\hline
\end{tabular}




\section{Conclusions}

We have demonstrated two all-organic materials that comprise heavy atoms and as a result display a dual emission at room temperature. Photoluminescence studies of compounds $\mathbf{1}$ and 2 show that the UV components of the spectra are consistent with fluorescence while the second emission observed in the visible region was long-lived phosphorescence. The phosphorescence observed from these compounds was strong, and it is believed to be due to the presence of the bromine and phosphorus atoms. These observations were made in solution as well as in PMMA films to exclude features associated with aggregations in the solid state. Compound $\mathbf{1}$ was used to fabricate experimental OLEDs. Here too, major contribution from electro-generated phosphorescence was observed at room temperature.

\section{Acknowledgements}

This work was supported by grants from NSF ECCS-1202439 and DMR-1006761.

\section{References}

[1] M. Klessinger, J. Michl, Excited States and Photochemistry of Organic Molecules, VCH, New York, 1995.

[2] J. Shinar, Organic Light-Emitting Devices-A Survey; Springer-Verlag: Berlin, 2003.

[3] M. A. Baldo, D. F. O'Brien, M. E. Thompson, S. R. Forrest, Phys. Rev. B, 60 (1999) 14422.

[4] M. A. Baldo, S. R. Forrest, Phys. Rev. B, 62 (2000) 10958.

[5] a) M. A. Baldo, D. F. O'Brien, Y. You, A. Shoustikov, S. Sibley, M. E. Thompson, S. R. Forrest, Nature, 395 (1998) 151. b) M. A. Baldo, S. Lamansky, P. E. Burrows, M. E. Thompson, S. R. Forrest, Appl. Phys. Lett. 75 (1999) 4. c) C. Adachi, M. A. Baldo, S. R. Forrest, M. E. Thompson, Appl. Phys. Lett. 77 (2000) 904.

[6] R. C. Evans, P. Douglas, C. J. Winscom, Coord. Chem. Rev. 250 (2006) 2093.

[7] M. Braun, J. Gmeiner, M. Tzolov, M. Coelle, F. D. Meyer, W. Milius, H. Hillebrecht, O. Wendland, J. U. von Schütz, W. Brütting, J. Chem. Phys. 114 (2001) 9625.

[8] A. S. Castillo, A. S. Carretero, J. M. Fernandez, W. J. Jin, A. F. Gutierrez, Anal. Chim. Acta, 516 (2004) 213.

[9] I. Goryacheva, S. Shtykov, G. Melnikov, E. Fedorenko, Environ. Chem. Lett. 1 (2003) 82.

[10] a) G. M. Escandar, A. Muñoz de la Peña, The Chemical Educator, 8 (2003) 251. b) C. P. McCaul, R. D. Ludescher, Photochem. Photobiol. 70 (1999) 166. c) H. R. Zhang, S. Y. Guo, L. Li, M. Y. Cai, Anal. Chim. Acta 463 (2002) 135. d) M. A. Gonzalez, M. H. Lopez, Analyst, 123 (1998) 2217. e) G. M. Escandar, M. A. Boldrini, Talanta, 53 (2001) 851.

[11] O. Bolton, K. Lee, H.-J. Kim, K. Y. Lin, J. Kim, Nature Chem. 3 (2011) 205.

[12] S. M. Ramasamy, R. J. Hurtubise, Microchem. J., 40 (1989) 317.

[13] R. J. Hurtubise, A. L. Thompson, S. E. Hubbard, Anal. Lett. 38 (2005) 1823.

[14] a) I. Sánchez-Barragán, J. Costa-Fernández, M. Valledor, J. Campo, A. Sanz-Medel, Trends in Anal. Chem. 25 (2006) 958. b) A. Salinas-Castillo, I. Sánchez-Barragán, J. M. Costa-Fernández, R. Pereiro, A. Ballesteros, J. M. González, A. Segura-Carretero, A. Fernández-Gutiérrez, A. SanzMedel, Chem. Commun. (2005) 3224.

[15] J. M. Traviesa-Alvarez, I. Sánchez-Barragán, J. M. Costa-Fernández, R. Pereiro, A. SanzMedel, Analyst, 132 (2007) 218.

[16] M. A. Baldo, M. E. Thompson, S. R. Forrest, Nature, 403 (2000) 750.

[17] I. Tanaka, Y. Tabata, S. Tokito, Chem. Phys. Lett. 400 (2004) 86.

[18] K. Goushi, R. Kwong, J. J. Brown, H. Sasabe, C. Adachi, J. Appl. Phys. 95 (2004) 7798.

[19] I. Tanaka, S. Tokito, J. Appl. Phys. 97 (2005) 113532.

[20] J. Demas, G. Crosby, J. Phys. Chem. 75 (1971) 991.

[21] C. Pérez-Bolívar, L. Llovera, S. E. Lopez, P. Anzenbahcer, Jr. J. Lumin. 130 (2010) 145.

[22] A. B. Padmaperuma, L. S. Sapochak, P. E. Burrows, Chem. Mater. 18 (2006) 2389.

[23] a) J. Pommerehne, H. Vestweber, W. Guss, R. F. Mahrt, H. Baessler, M. Porsch, J. Daub. Adv. Mater. 7 (1995) 551. b)L. S. Sapochak, A. B. Padmaperuma, P. A. Vecchi, H. Qiao, P. E. Burrows, Proc. of SPIE 6333, (2006) 63330F. 
[24] P. Calcagno, B. M. Kariuki, S. J. Kitchin, J. M. A. Robinson, D. Philp, K. D. M. Harris, Chem. Eur. J. 6 (2000) 2338.

[25] P. E. Burrows, A. B. Padmaperuma, L. S. Sapochak, P. Djurovich, M. E. Thompson, Appl. Phys. Lett. 88 (2006) 183503. 